\title{
LA COMUNICACIÓN PARA LA PAZ COMO HERRAMIENTA DE TRANSFORMACIÓN SOCIAL
}

\section{COMMUNICATION FOR PEACE AS A SOCIAL TRANSFORMATION TOOL}

\author{
Augusto Renzo Espinoza Bonifaz \\ Maestro en Ciencias Penales \\ Universidad de San Martín de Porres \\ aespinozab@usmp.pe
}

Perú

\section{SUMARIO}

- Introducción

- Comunicación para la paz

- Estándares mínimos de la comunicación para la paz

- Criterios para determinar la existencia de una comunicación para la paz

- Situación de la comunicación a través de los medios de radiodifusion

- Agenda pendiente para una comunicación para la paz

- Conclusiones

\section{RESUMEN}

El presente artículo propone utilizar el concepto de comunicación para la paz como herramienta para mejorar la calidad de información difundida por los medios de comunicación. En primer lugar se busca construir una definición de comunicación para la paz, y establecer los estándares mínimos que importa este tipo de comunicación social. Luego, se pretende establecer ciertos criterios que permitan identificar su presencia en los medios de comunicación, y proponer reformas en las políticas públicas respectivas, no sin antes realizar un análisis utilizando estadísticas sobre la situación actual de nuestra radio $\mathrm{y}$ televisión.

\begin{abstract}
This article proposes to use the concept of communication for peace as a tool to improve the quality of information disseminated by the media. Firstly, it seeks to build a definition of communication for peace, and establish the minimum standards that this type of social communication matters. Then, it is intended to establish certain criteria to identify their presence in the media, and propose reforms in the respective public policies, but not before performing an analysis using statistics on the current situation of our radio and television.
\end{abstract}

\section{PALABRAS CLAVES}

Comunicación para la paz, medios de comunicación, control social.

\section{KEYWORDS}

Communication for peace, media, social control.

“Tengo la esperanza de que los periódicos sean mejores y, a la postre, que la televisión también lo sea. Y además, aunque la mía fuera una batalla perdida de antemano, no me importa. Como decía Guillermo d'Orange, no es necesario esperar para emprender, ni lograr para perseverar."

Giovanni Sartori. 


\section{INTRODUCCIÓN}

Actualmente, los medios de comunicación, especialmente los noticieros, nos muestran una extensa y repetida cobertura de eventos violentos, como crímenes, reflejando un profundo interés por informar que vivimos en una sociedad en conflicto. Así, el ciudadano, está convencido de que nos encontramos en un espacio colectivo sumamente peligroso, por ende, siente miedo y desconfía de los demás.

De esta manera, se pueden identificar hasta tres consecuencias negativas de ver hechos violentos en los medios de comunicación (Gascón: 2008, p.26):

Efectos directos en la conducta (se aprenden patrones de pensamiento que apoyan comportamientos agresivos; se favorece la ansiedad, se disminuye el autocontrol, aumentan las conductas violentas o el uso de la violencia para resolver conflictos), desensibilización (menos sensibles a la violencia próxima, menos sensible al dolor y sufrimiento de los otros o más disposición a tolerar los niveles de violencia social) y percepción distorsionada de la realidad (visión negativa del mundo, percepción del mundo como peligroso o percepción miserable del ser humano).

En este sentido, los niveles de violencia que transmiten los medios de comunicación y sus efectos son coherentes con las estrategias de control social de los grupos de poder al afectar a la organización colectiva de los ciudadanos y sus deseos de participar en los procesos de cambio social. Por ejemplo, la menor sensibilidad al dolor y al sufrimiento de los otros favorece el individualismo y la indiferencia. Por su parte, la percepción del mundo de manera negativa (un entorno peligroso y miserable) genera pesimismo, desconfianza y miedo que restringe la participación en el espacio colectivo. De esta manera, el cambio y la transformación social se contemplarán como poco probables. Será frecuente la idea de que todo está malo y nada se puede hacer (Arévalo: 2014, p. 58).

Además, de que se permite que el control social formal, es decir, el poder punitivo del Estado se extienda cada vez más, pues erróneamente se piensa que la solución para eliminar estos hechos violentos consiste en criminalizar nuevas conductas y castigar de manera más drástica los delitos ya existentes.

\section{COMUNICACIÓN PARA LA PAZ}

El concepto de cultura de paz fue adoptado el 6 de octubre de 1999 en la resolución 53/243 de la Asamblea General de las Naciones Unidas, con el nombre "Declaración y Programa de Acción sobre una Cultura de Paz". El artículo primero de la mencionada Declaración define que la cultura de paz es un conjunto de valores basados en:

El respeto a la vida, el fin de la violencia y la promoción y la práctica de la no violencia por medio de la educación, el diálogo y la cooperación. La adhesión a los principios de libertad, justicia, democracia, tolerancia, solidaridad, cooperación, pluralismo, diversidad cultural, diálogo y entendimiento a todos los niveles de la sociedad y entre las naciones; $y$ animados por un entorno nacional e internacional que favorezca a la paz.

Adaptando este concepto de cultura de paz al plano de la comunicación social podríamos señalar que una comunicación para la paz buscaría promover el fin de la violencia:

1. Incentivando el entendimiento de los conflictos que ocurren en la sociedad, a través de información que permita comprender que estos derivan de problemas estructurales.

2. Impulsando un diálogo alturado entre los actores de la sociedad civil, que motive a la ciudadanía a confiar que la transformación del conflicto es posible $\mathrm{y}$, por consiguiente, buscar soluciones a los problemas estructurales identificados.

3. Generando espacios de debate inclusivo, en donde se respeten todas las opiniones de los representantes de los distintos sectores sociales, lo cual permitirá reconocer la interculturalidad y la interdependencia social existente, pues todos nos vemos afectados ante un conflicto social, aunque estos hechos se produzcan en una distancia lejana.

4. Estimulando una sociedad civil proactiva y sensible ante los abusos de poder, que participe vivamente en los procesos de transformación social. 
En este sentido, resulta evidente que la comunicación para la paz busca forjar un compromiso y un posicionamiento claro sobre los problemas estructurales que aquejan al Estado, y por ende a la sociedad.

\section{ESTÁNDARES MÍNIMOS DE LA COMUNICACIÓN PARA LA PAZ}

El empleo de los estándares de la comunicación para la paz transforman significativamente los lineamientos para la elaboración y presentación de una noticia, pues en su preparación prevalece la calidad de su contenido por sobre los intereses económicos, ya que existe por sobre todo la profunda preocupación por explicar de manera objetiva y ética las causas que ocasionan un hecho noticioso, y su posible solución.

De esta manera, el periodista investiga responsablemente los factores que originan un acontecimiento, por ejemplo, un crimen. Para ello, es sumamente neutral, explora la noticia desde todos los ángulos, humaniza a sus actores y presta atención a los problemas estructurales que han contribuido con dicho suceso, buscando descubrir la posible solución del conflicto y no exagerando o dramatizándolo.

Tehranian (Espinar \& Hernández: 2012, p.182) elaboró diez recomendaciones para elaborar una noticia que satisfaga los estándares de la comunicación para la paz:

1. No reducir nunca las partes de un conflicto a dos.

2. Identificar las posiciones y los intereses de todas las partes en conflicto.

3. No caer presa de una sola fuente.

4. Desarrollar un buen sentido del escepticismo. Recordar que la información es una representación. El sesgo es inherente a la condición humana.

5. Dar voz a las víctimas y a los implicados en tareas de construcción de paz para representarlos y empoderarlos.

6. Buscar soluciones pacíficas a los problemas del conflicto pero no caer en panaceas.

7. La representación mediática del conflicto puede convertirse en parte del problema si acentúa los dualismos y odios.
8. La representación mediática del conflicto puede convertirse en parte de la solución si hace uso de las tensiones creativas presentes en todo conflicto para indagar en los aspectos compartidos y las respuestas no violentas.

9. Respetar siempre los principios éticos profesionales de precisión, veracidad, equidad $\mathrm{y}$ respeto por la dignidad y los derechos humanos.

10. Trascender los propios sesgos étnicos, nacionales o ideológicos para identificar y representar a todas las partes de manera justa y precisa.

\section{CRITERIOS PARA IDENTIFICAR LA EXISTENCIA DE UNA COMUNICACIÓN PARA LA PAZ}

Ante lo expuesto, es trascendental identificar los criterios que nos permitan identificar si en la actualidad nuestros medios de comunicación social emplean los estándares de la comunicación para la paz en la elaboración y difusión de sus noticias. En este sentido Arévalo (2014, p. 71) ha detallado cuatro criterios que pueden contribuir para tal evaluación.

\section{Denuncia activa de injusticias y su efec- to en la transformación de la violencia}

Este criterio mide la difusión de temas relacionados a la vulneración de derechos humanos y problemas estructurales. Se debe evaluar la cantidad de estas noticias en comparación con el total, así como su ubicación espacial y temporal dentro de un noticiero.

Si este tipo de noticias ocupan un lugar central en los programas periodísticos de gran audiencia es indicativo de la existencia de una comunicación para la paz. Por otro lado, también se debe analizar si la propagación de estas noticias produjo intervención de las autoridades políticas en la solución de los problemas proyectados.

Asimismo, los medios de comunicación necesitan hacer periodismo preventivo, enfocando los problemas antes de que estos se generalicen o intensifiquen. Por ejemplo, si a diario se producen delitos patrimoniales, una noticia sobre este tema debería analizar los factores y medidas para prevenir este problema. 


\section{Visibilizar noticias positivas y puntos comunes}

Inclusión de contenidos positivos en los medios de comunicación, es decir, difusión de acontecimientos que demuestren mejoras en determinados sectores problemáticos o de conflicto social, de tal manera que, ello genere confianza en la población de la existencia de un avance al respecto y, la posibilidad de una potencial solución.

Este tipo de noticias empoderan a la sociedad al mostrar que no todo lo que sucede en su entorno es negativo, equilibrando por consiguiente el tratamiento informativo que en la actualidad tiende a mostrar solo una visión pesimista y violenta de la sociedad.

Este criterio se mide igualmente considerando la cobertura en número, tiempo y ubicación de este tipo de información en el marco general de la programación periodística.

\section{Enfoque incluyente y diverso en la selección de los temas y las fuentes periodisticas}

A nivel temático, se mide la diversidad en la selección de tópicos noticiosos para verificar la inserción de hechos que normalmente son acallados y que son importantes socialmente. Por el lado de las fuentes de información, se analiza la presencia de un enfoque incluyente en la narración y presentación de la noticia (por ejemplo, las opiniones de los ciudadanos, los protagonistas del hecho informado, etc.) en comparación con las fuentes regularmente citadas (opiniones de las autoridades políticas, etc.).

Una comunicación para la paz busca ampliar y activar el dialogo entre los diversos sectores de la sociedad, y no ser únicamente una vitrina para los poderosos.

\section{La contextualización}

Importa la existencia de datos que permitan el entendimiento de los problemas y/o conflictos que divulgan las noticias, pues lamentablemente la descontextualización y la superficialidad son notas características del actual tratamiento periodístico.

Vemos que a los medios de comunicación les agrada darle vueltas a un mismo hecho sin dar mayores explicaciones sobre el mismo, generando miedos y distanciamientos innecesarios.

Lo que se busca es que la noticia realice un tratamiento profundo del acontecimiento, que busque descubrir las causa y los factores del problema, y no tan solo detallar el síntoma. Por ejemplo, en una noticia sobre un delito de feminicidio, el periodista no debe limitarse a describir el hecho delictivo de manera sensacionalista, ni tampoco mencionar que suerte correrá el presunto autor del crimen, sino ahondar en los motivos que lo llevaron a cometer tal hecho, como la actual coyuntura en salud mental pública no garantiza un servicio idóneo para los ciudadanos que tienen problemas emocionales, como la aun en nuestra sociedad existen aún patrones "machistas" de conducta y qué hacer para erradicarlos, etc.

\section{SITUACIÓN DE LA COMUNICACIÓN A TRAVES DE LOS MEDIOS DE RADIODIFUSIÓN}

En el presente acápite expondremos la situación actual de la radio y la televisión en nuestro país, para ello describiremos como se encuentra regulada normativamente la prestación del servicio de radio y televisión, indicando el rol que desempeñan las autoridades y asociaciones existentes en este sector; luego, expondremos la situación actual de la radio y televisión en nuestro país, y la percepción que tiene la ciudadanía sobre el contenido de la comunicación radial y televisiva basándonos en encuestas y estudios realizados recientemente.

\section{Regulación normativa de la radiodifusión}

\section{Autoridades competentes}

El Ministerio de Transportes y Comunicaciones es el órgano del Poder Ejecutivo, responsable del desarrollo de los sistemas de transporte, la infraestructura de las comunicaciones y telecomunicaciones del país. Su labor es crucial para el desarrollo socio-económico porque permite la integración nacional, regional e internacional, la facilitación del comercio, la reducción de la pobreza y el bienestar del ciudadano. 
De esta manera, se constituye como el ente rector, y en cuanto a las comunicaciones, a través de los órganos competentes, tiene a su cargo la evaluación y tramitación de las solicitudes relacionadas con la operación de estaciones de radio y televisión de señal abierta y servicios privados de telecomunicaciones, además de la planificación del espectro radioeléctrico que utilizan las mismas. También ejerce la función de controlar y supervisar la prestación de los servicios y actividades de comunicaciones, con la potestad para sancionar en el ámbito de su competencia y de velar por el uso correcto del espectro radioeléctrico.

La Dirección General de Control y Supervisión de Comunicaciones es el órgano de línea que se encarga de controlar y supervisar la prestación de los servicios y actividades de comunicaciones. Tiene la potestad para sancionar en el ámbito de su competencia, así como velar por el uso correcto del espectro radioeléctrico.

El Consejo Consultivo de Radio y Televisión, es un órgano adscrito al Ministerio de Transportes y Comunicaciones. Está conformado por 11 miembros, representantes de:

- La Asociación Nacional de Centros.

- Los titulares de autorizaciones de servicios de radiodifusión sonora y de televisión comercial.

- Los titulares de autorizaciones de servicios de radiodifusión sonora y de televisión educativa.

- El Consejo de la Prensa Peruana.

- Las Asociaciones de Consumidores.

- Las Facultades de Comunicación Social y Periodismo.

- El Ministerio de Transportes y Comunicaciones (solo con derecho a voz).

- El Colegio de Periodistas del Perú.

- La Asociación Nacional de Anunciantes (ANDA).

- El Colegio Profesional de Profesores del Perú.
Entre sus principales funciones y atribuciones están:

- Actuar como veedores en los concursos públicos donde se otorgan las autorizaciones para brindar los servicios de radio $\mathrm{y}$ televisión.

- Establecer un sistema de otorgamiento anual de premios y reconocimientos a personas $u$ organizaciones que contribuyan al desarrollo integral y cultural del país mediante su trabajo en la radio y/o televisión.

- Propiciar investigaciones académicas que promuevan el mejoramiento de la radio y televisión.

- Apoyar iniciativas con fines académicos para la preservación y archivo de los programas de producción nacional transmitidos en la radio y televisión.

- Emitir una opinión no vinculante dentro del procedimiento administrativo sancionador a los servicios de radio y televisión, cuando se cometan las siguientes infracciones:

$\diamond$ Incumplir injustificadamente la transmisión de los programas que hayan sido promocionados en la fecha, horario o con las características de contenido o duración anunciadas.

$\diamond$ Incumplimiento de las normas relativas al horario de protección familiar (06:00 22:00).

$\diamond$ Incumplimiento de las disposiciones del Código de Ética.

$\diamond$ Incumplimiento de las condiciones esenciales y otras establecidas en la autorización.

\section{Asociaciones civiles}

La Sociedad Nacional Radio y Televisión tiene el objeto de representar a sus asociados en cuanto a ser el ente gremial que los agrupa en el desarrollo que éstos realizan del servicio de radiodifusión comercial y la producción televisiva y radial, procurando promover el crecimiento y consolidación de los servicios de radiodifusión comercial y la producción televisiva y radial en todo el Perú; defendiendo los principios básicos de la radiodifusión privada, con especial atención en la defensa de 
los principios de la libre y leal competencia; participando de manera activa, propiciando y organizando seminarios, conversatorios, diálogos y reuniones con autoridades políticas, públicas o privadas, en especial las que tienen a su cargo la labor reguladora de las comunicaciones. También se constituyó para propiciar el desarrollo y actuar en permanente defensa y protección de la libertad de expresión.

Cabe resaltar que, los miembros de la Sociedad Nacional de Radio y Televisión en su calidad de prestadores de servicios de radiodifusión, propusieron regir sus actividades conforme a un Código de Ética común que contribuya a proteger y respetar los derechos fundamentales de la persona, así como los valores nacionales que reconoce la Constitución Política del Perú. Asimismo, sus asociados suscribieron un Pacto de Autorregulación, en aras de fomentar el desarrollo de la industria de la radio y la televisión privada comercial, y mantener vigentes y actuales los valores de: veracidad y respeto a la dignidad de la persona humana como principios fundamentales y reglas de la actividad, todo ello dentro del marco de responsabilidad con la sociedad peruana, y en atención a sus particulares circunstancias sociales, culturales y educativas que buscan promover el respeto hacia la persona, la familia, la sociedad y la legislación vigente.

La Asociación Nacional de Anunciantes del Perú tiene el objeto de propiciar una comunicación comercial honorable, respetuosa de la dignidad y condición humana, con especial consideración hacia la familia y sus valores fundamentales, que aliente el desarrollo de las cualidades superiores del ser humano y contribuya al progreso de la comunidad. Entre sus principales objetivos están: preservar y defender la máxima libertad en el ámbito de la comunicación comercial y social, en especial en el caso de la publicidad que es su principal manifestación; $\mathrm{y}$, promover la autorregulación publicitaria, la lealtad entre competidores y la protección del público consumidor,

\section{Normatividad vigente}

El artículo 1 de la Constitución Política establece que: "La defensa de la persona humana y el respeto de su dignidad son el fin supremo de la sociedad y del Estado.", asimismo, el numeral 4 del artículo 2 establece que toda persona tiene derecho a: "las libertades de información, opinión, expresión y difusión del pensamiento mediante la palabra oral o escrita o la imagen, por cualquier medio de comunicación social, sin previa autorización ni censura ni impedimento algunos, bajo las responsabilidades de ley." En este sentido, el articulo 14 in fine prescribe que: "Los medios de comunicación social deben colaborar con el Estado en la educación y en la formación moral y cultural."

Por otro lado, el artículo 65 establece que: "El Estado defiende el interés de los consumidores y usuarios. Para tal efecto garantiza el derecho a la información sobre los bienes y servicios que se encuentran a su disposición en el mercado. Asimismo vela, en particular, por la salud y la seguridad de la población."

En materia de comunicaciones existen diversas normas que regulan el sector, siendo una de ellas el Texto Único Ordenado de la Ley de Telecomunicaciones, que declara de necesidad pública el desarrollo de las Telecomunicaciones como instrumento de pacificación y de afianzamiento de la conciencia nacional, precisa en su artículo 1 que las Telecomunicaciones son un vehículo de pacificación y desarrollo.

De manera más específica, en cuanto a normar la prestación de los servicios de radiodifusión, sea sonora o por televisión de señal abierta, existe la Ley de Radio y Televisión, con su respectivo Reglamento. Esta norma precisa que los servicios de radiodifusión son servicios privados de interés público, prestados por una persona natural o jurídica, privada o pública, cuyas emisiones se destinan a ser recibidas directamente por el público en general; y tienen por finalidad satisfacer las necesidades de las personas en el campo de la información, el conocimiento, la cultura, la educación y el entretenimiento, en un marco de respeto de los deberes y derechos fundamentales, así como de promoción de los valores humanos y de la identidad nacional.

Asimismo, establece los principios que rigen la prestación de los servicios de radiodifusión:

1. La defensa de la persona humana y el respeto a su dignidad.

2. La libertad de expresión, de pensamiento y de opinión. 
3. El respeto al pluralismo informativo, político, religioso, social y cultural.

4. La defensa del orden jurídico democrático, de los derechos humanos fundamentales y de las libertades consagradas en los tratados internacionales y en la Constitución Política.

5. La libertad de información veraz e imparcial.

6. El fomento de la educación, cultura y moral de la Nación.

7. La protección y formación integral de los niños y adolescentes, así como el respeto de la institución familiar.

8. La promoción de los valores y la identidad nacional.

9. La responsabilidad social de los medios de comunicación.

10. El respeto al Código de Normas Éticas.

11. El respeto al honor, la buena reputación y la intimidad personal y familiar.

12. El respeto al derecho de rectificación.

En resumen, los servicios de radiodifusión, sonora y de televisión deben contribuir a proteger o respetar los derechos fundamentales de las personas, así como los valores nacionales que reconoce la Constitución Política del Perú.

Para la prestación de los servicios de radiodifusión, en cualquiera de sus modalidades, se requiere contar previamente, con autorización otorgada por el Ministerio de Transportes y Comunicaciones. Uno de los requisitos para su expedición es la presentación de un Código de Ética, en el que se incluirán disposiciones relativas al horario familiar, mecanismos concretos de autorregulación, mecanismos para solución de quejas o comunicaciones del público relacionadas con la programación, aplicación del Código de Ética y/o ejercicio del derecho de rectificación, y la regulación de la cláusula de conciencia; los Códigos deben ser remitidos al Ministerio de Transportes y Comunicaciones, y puestos en conocimiento del público.

La Ley de Radio y Televisión también tipifica las infracciones en las que pueden incurrir los titulares de los servicios de radiodifusión, clasificándolas en: leves, graves, y muy graves.
Entre ellas tenemos:

- La no presentación del Código de Ética (leve).

- La negativa, obstrucción o resistencia al ejercicio de las facultades de supervisión y control (grave).

- El incumplimiento de las normas relativas al horario familiar y de protección al menor (grave).

- El incumplimiento de las disposiciones del Código de Ética (grave).

Las posibles sanciones a imponerse son la amonestación, multa, y cancelación. Tratándose de infracciones leves, la autoridad puede disponer alternativamente a la multa, la sanción de amonestación. La cancelación de la autorización podrá ser dispuesta para los casos de la comisión reiterada de infracciones calificadas como muy graves o en caso de incumplimiento de la medida cautelar de suspensión de la autorización.

Las multas serán aplicables de acuerdo con las siguientes escalas:

- Leve: de 1 UIT hasta 10 UIT.

- Grave: de más de 10 UIT hasta 30 UIT.

- Muy grave: de más de 30 UIT hasta 50 UIT.

Para la aplicación y graduación de la multa, se tomará en cuenta los siguientes criterios:

1. Naturaleza y gravedad de la infracción;

2. Daño causado por la infracción;

3. Reincidencia en la infracción;

4. Disposición del infractor a reparar el daño o mitigar sus efectos;

5. Beneficio obtenido como consecuencia de la infracción;

6. La repercusión social, así como las características de la localidad en la que opera;

7. Los aspectos demográficos y la cantidad poblacional. 
Sin perjuicio de la imposición de sanciones, el personal autorizado del Ministerio podrá adoptar y ejecutar medidas correctivas inmediatas destinadas a prevenir, impedir o cesar la comisión del hecho infractor.

Asimismo, los titulares de estaciones del servicio de radiodifusión deberán atender las quejas relativas al incumplimiento del Código de Ética formuladas por el público en general. Una vez agotada la queja ante el titular de la autorización, se puede recurrir en vía de denuncia ante el órgano competente del Ministerio por la presunta infracción. Este procedimiento será aplicable también a las solicitudes relacionadas al ejercicio del derecho de rectificación establecido en la Ley N $\mathrm{N}^{\circ} 26847$.

\section{Estadisticas sobre los medios de radiodifusión}

El área de Comunicaciones e Imagen del Consejo Consultivo de Radio y Televisión anualmente (desde el 2010 hasta el presente año) ha elaborado estudios cuyo objetivo consiste en recopilar información proporcionada por la Dirección General de Autorizaciones en Telecomunicaciones y la Dirección General de Control y Supervisión de Comunicaciones del Ministerio de Transportes y Comunicaciones sobre los principales indicadores de radio y televisión en el Perú: número de estaciones, número de titulares, estaciones según finalidad (comercial, educativa, comunitaria), titulares de radio y TV pública/estatal, y la situación de los Códigos de Ética de los titulares de radio y televisión.

El último de estos estos estudios, de acuerdo a información recopilada en enero y febrero de 2016, nos brinda los siguientes datos:

Número de estaciones de radio y televisión a nivel nacional y finalidades

Actualmente existen 1,403 estaciones de televisión; de las cuales 805 son de finalidad comercial, 598 son educativas, y no existen comunitarias. Respecto a las estaciones de radio existen 4,281; de las cuales 3,415 tienen finalidad comercial, 863 educativa, y 3 son comunitarias.

\section{Situación de los Códigos de Ética}

Respecto a la presentación de los Códigos de Ética por parte de los titulares de radio y televisión, sólo 455 han presentado, no habiéndolo hecho 2,291.

\section{Sanciones}

Durante el año 2015, fueron sancionados 214 titulares de radio y televisión, y se cometieron 278 infracciones. Las infracciones más recurrentes fueron: prestación y uso de frecuencias del servicio de radiodifusión sin autorización con 89 , cambio de característica técnica de equipos de radiodifusión con 88 , y operación de equipos de radiodifusión no homologados con 86. Por no presentar Código de Ética fueron 7, y por incumplir disposiciones del Código de Ética sólo 1.

\section{Estudios sobre consumo y contenido en los medios de radiodifusión}

\section{Estudio sobre consumo radial y televisivo - 2015}

Entre mayo y julio del año 2015, Lima Consulting - ganadora de la Adjudicación Directa Pública 001-2015-MTC/CONCORTV - a pedido del Consejo Consultivo de Radio y Televisión (CONCORTV), realizó una encuesta cuyo objetivo busco conocer las actitudes, hábitos y opinión con respecto a la radio y televisión en el Perú. Los principales temas indagados en la investigación fueron: tenencia de equipos, nivel de uso y hábitos de consumo de medios, programas más vistos, control parental sobre el consumo de radio y televisión en menores de edad, grado de satisfacción con los medios, entre otros.

La cobertura del estudio fue de 21 ciudades del Perú: Lima y Callao, Arequipa, Ayacucho, Cajamarca, Chiclayo, Chimbote, Cusco, Huancayo, Huánuco, Huaraz, Ica, Iquitos, Juliaca, Moquegua, Piura, Pucallpa, Puno, Tacna, Tarapoto, Trujillo y Tumbes. En un universo de hombres y mujeres de 18 años a más, de los niveles socioeconómicos $\mathrm{A}$, B, C, D y E. Cuyo diseño muestral fue de 9,266 personas: 1,121 en Lima y Callao y aproximadamente 407 en cada una de las 20 ciudades restantes.

\section{Tenencia de equipos y servicios}

A nivel nacional, el televisor (98.5\%), el celular $(93.2 \%)$ y la radio $(92 \%)$ son los equipos más presentes en los hogares peruanos. Entre Lima 
y provincia, la mayor diferencia se da respecto a la tenencia de Internet, siendo mayor en la ciudad de Lima (48.5\%).

La tenencia de la televisión por suscripción se incrementó en $2 \%$ a comparación de hace dos años, siendo Iquitos $(+20.3 \%)$, Arequipa $(+17.4 \%)$, Huánuco $(+17.4 \%)$ y Pucallpa $(+14 \%)$ las ciudades con mayor crecimiento. Las principales razones por las que cuentan con este servicio son: la variedad de programas $(58 \%)$, mejor captación de los canales $(34 \%)$, el entretenimiento $(28 \%)$ y porque están insatisfechos con la programación nacional (19\%).

\section{Hábitos de consumo de medios}

A nivel nacional, la televisión es el medio de comunicación de mayor consumo, llegando a alcanzar el $100 \%$ en ciudades como Piura, Trujillo y Pucallpa. A comparación de 2013, el uso de Internet ha crecido en 7\% (de lunes a viernes) y en 6\% (sábados y domingos), mientras que el consumo de radio disminuyó en $4 \%$ (de lunes a viernes) y en $8 \%$ (sábados y domingos).

En el caso de los fines de semana, las ciudades con mayor consumo de televisión son Huaraz (97\%), Ica (97\%) y Pucallpa (95.4\%) y las de menor consumo son Puno (78.5\%), Cusco (87\%) y Juliaca (87.3\%).

Entre ver televisión, escuchar radio, leer diarios/revistas y navegar por Internet, los peruanos dedican alrededor de 10 horas diarias al consumo de medios de comunicación. Los principales tipos de programas de TV que se ven en familia son los infantiles $(40.3 \%)$, de entretenimiento $(37.8 \%)$, películas $(35.4 \%)$, series/miniseries/novelas (33.2\%) y noticiarios $(30.9 \%)$.

Al preguntar a los entrevistados por los programas de televisión más vistos, mencionaron en primer lugar a "Al Fondo Hay Sitio" (19\%), seguido de "Esto es Guerra" (16\%), América Noticias Edición Central (15\%), y América Noticias Primera Edición $(14 \%)$.

En la radio, los programas más escuchados en familia son los musicales (85\%), noticiarios (51\%) y programas de entretenimiento (7\%); existen casos puntuales donde los noticiarios obtuvieron un porcentaje más alto que los programas musicales, por ejemplo, en las ciudades de Iquitos (60\%) y Puno (73\%).

\section{Evaluación de medios}

Existen significativos cambios respecto a la evaluación de la TV a comparación de los resultados de 2013, presentando un decrecimiento considerado en cuanto a valoraciones positivas como "el medio más neutral" $(-23 \%)$, veraz $(-19 \%)$, plural $(-18 \%)$, “el más informativo" $(-17 \%)$, "el que seguirá vigente en 20 años" (-16\%), “el más entretenido" (-16\%), "cercano a la gente" $(-15 \%)$, y "el más educativo" (-14\%).

A nivel nacional, son vistos de manera frecuente y muy frecuente en la TV los siguientes contenidos: violencia (78\%), palabras groseras/insultos (63\%), situaciones de mal ejemplo para la sociedad $(62 \%)$, trato discriminatorio (57\%), escenas de sexo/ desnudos $(50 \%)$ y contenidos para adultos en horario familiar $(40 \%)$.

Respecto a la violencia, para el $60 \%$ de los encuestados solamente debería difundirse después de las 10 p.m. y con advertencia, mientras que para el $31 \%$ nunca debería emitirse en televisión, este porcentaje se eleva en ciudades como Cajamarca (65\%), Ayacucho $(62 \%)$, y Juliaca $(50 \%)$.

En la radio, los contenidos inadecuados con mayor presencia son las palabras groseras/ insultos $(17 \%)$, violencia $(17 \%)$, situaciones de mal ejemplo para la sociedad (14\%), trato discriminatorio (14\%), y frases de connotación sexual $(13 \%)$.

Para el 62\% de los encuestados las palabras soeces e insultos nunca deberían emitirse en la radio, siendo más pronunciado en ciudades como Piura (78\%) y Tumbes $(76 \%)$, en los niveles socioeconómicos A (68\%) y B (66\%), en las mujeres (69\%) y en las personas adultas mayores $(75 \%)$.

Del mismo modo, el $66 \%$ de los encuestados considera que las frases de connotación sexual o de doble sentido nunca deberían emitirse en la radio. Dicha cifra se incrementa en ciudades como Ayacucho (91\%) y Huancayo (83\%), en los niveles socioeconómicos D (71\%) y $\mathrm{E}$ $(65 \%)$, en las mujeres (73\%) y en las personas adultas mayores $(78 \%)$. 
El $48 \%$ de peruanos opina que ver noticias sobre delitos contra las personas sirve para estar informados. Esta cifra se incrementa en ciudades como Cajamarca (67\%), Ayacucho (66\%), y Chiclayo (64\%); en los niveles socioeconómicos A (53\%) y E (49\%), en los hombres (49\%) y en los adultos mayores (54\%). El $10 \%$ de la población peruana no le encuentra utilidad a las noticias sobre delitos, calificándolas de morbosas.

Las noticias sobre violencia que han llamado más la atención de los ciudadanos son sobre casos de violencia contra niños, mujeres y adultos mayores (48\%), y las noticias sobre adolescentes que cometen delitos (25\%).

Para el 69\% de encuestados los personajes de la TV o del espectáculo son quienes aparecen más favorecidos en la televisión. Dicha cifra se incrementa en ciudades como Ayacucho (78\%), Iquitos y Piura (77\%).

La percepción negativa de cómo la televisión muestra a los grupos sociales de mujeres, personas adultas mayores, y niños y niñas ha aumentado en comparación al 2013. En cuanto a los grupos de personas indígenas y homosexuales, esta percepción negativa se da en un $31 \%$ y $23 \%$, respectivamente.

\section{Control parental}

Del total de hogares que cuentan con menores de 14 años a nivel nacional, el $84 \%$ de los encuestados afirma que existe control en el hogar sobre el tiempo que los niños y adolescentes ven la televisión, una disminución del 3\% a comparación de hace dos años. Este resultado contrasta con las respuestas de la misma pregunta formulada a los niños y adolescentes, quienes en una encuesta realizada en el 2014, solo el 72\% afirmó que les habían puesto reglas o condiciones para ver televisión.

Del total de hogares que cuentan con menores de 14 años a nivel nacional, el $64 \%$ de los encuestados afirma que existe control en el hogar sobre los tipos de programas que los niños y adolescentes ven en televisión.

La principal forma de control utilizada en los niños y adolescentes es dejarlos ver la televisión hasta cierta hora (54\%), principalmente hasta las nueve de la noche o antes (87\%), aunque dicha cifra disminuye considerablemente cuando se les consulta a los propios niños y adolescentes (32\%). El tipo de control a través del visionado de programas con compañía adulta ha aumentado de $9 \%$ a $18 \%$ en dos años.

El $76 \%$ de los encuestados asegura que tiene la costumbre de comentar con los niños sobre los programas de televisión que ven en familia, una disminución del $1 \%$ a comparación de hace dos años. Este resultado contrasta con las respuestas de la misma pregunta formulada a los niños y adolescentes, quienes en una encuesta realizada en el 2014, solo el $20 \%$ afirmó que sus padres comentan con ellos sobre lo que ven en la televisión.

\section{Regulación de los medios}

El $61 \%$ de peruanos cree que la radio y TV no son reguladas, solo el $6.5 \%$ afirmó que son reguladas por el Ministerio de Transportes y Comunicaciones (MTC).

El $55 \%$ de los peruanos tiene conocimiento del horario familiar que va de las 6:00 a las 22:00 horas, donde se prohíbe la transmisión de contenidos violentos y obscenos. Las ciudades en las que dicha cifra asciende son Arequipa (66\%), Moquegua (63\%) y Huaraz $(62 \%)$. Mientras que las ciudades con mayor porcentaje de desconocimiento del horario familiar son Ayacucho (63\%), Tumbes, Juliaca (61\%) y Piura (60\%).

Solo el $48 \%$ de peruanos sabe que puede quejarse ante los propios medios de comunicación por los contenidos que atenten contra el horario familiar. Esta cifra asciende en Chiclayo (67\%) y Pucallpa (59\%).

\section{Consumo de radio y televisión}

El porcentaje de consumo diario de la televisión local es dispar, dependiendo de las ciudades encuestadas. Los mayores consumidores diarios de televisión local (sin incluir Lima y Callao) se encuentran en Huaraz (69), Pucallpa $(63 \%)$ y Tarapoto $(63 \%)$, mientras que en Huánuco (10\%), Ayacucho (12\%) y Huancayo (14\%) el consumo diario es bajo.

En cuanto a la radio local, el 48\% afirma escuchar radio de su localidad todos los días. Sin incluir Lima y Callao, la cifra se incrementa considerablemente en ciudades como Huaraz $(60 \%)$ y Arequipa $(53 \%)$, mientras que en Chimbote $(9 \%)$, Ica $(11 \%)$ y Piura $(13 \%)$ el consumo diario es bajo. 
A nivel nacional, el porcentaje de satisfacción de los encuestados con los canales locales es de $33 \%$. El mayor grado de satisfacción se encuentra en Trujillo (76\%), Tarapoto (52\%) y Cusco (49\%). En el caso de las radios locales, el porcentaje de satisfacción es de $64 \%$, lo cual representa una disminución del 11\% en comparación al 2013. El mayor grado de satisfacción se encuentra en Trujillo (77\%), Lima y Callao (69\%) y Tarapoto (67\%).

\section{Análisis comparativo de los principales noticieros de televisión en señal abierta de la ciudad de Lima - 2015}

De agosto a octubre del año 2014 la empresa Ad-Rem - ganadora de la Adjudicación Directa Pública- a pedido del Consejo Consultivo de Radio y Televisión realizo una encuesta cuyo objetivo fue hacer un análisis e interpretación comparativa de los noticiarios de señal abierta de Lima transmitidos de lunes a domingo para precisar las características y mensajes que transmiten y el cumplimiento de las disposiciones señaladas en el Horario Familiar.

Los principales temas indagados son el ámbito de la noticia, alcance de las notas nacionales, formato de las notas, comentarios, áreas temáticas, actores sociales, grupos favorecidos y desfavorecidos, recursos de producción, calidad periodística, ética periodística, participación de cada bloque en el tiempo de duración del noticiario y proporción entre el tiempo de duración de las noticias y el tiempo destinado a comerciales.

La cobertura del estudio fue en la ciudad de Lima y Huancayo, departamento de Junín. El Universo fueron los principales noticiarios de señal abierta de Lima: "90 Central" (Frecuencia Latina), "América Noticias Edición Central" (América Televisión), "24 Horas Edición Central" (Panamericana Televisión), "TV Perú Noticias" (TV Perú), "ATV Noticias Edición Central" (Andina de Televisión) y "RBC Informa" (RBC); de cable: "De 6 a 9" (Canal $\mathrm{N})$; y, en provincias se incluyó emisiones del canal UNITEL TV, Canal 31 y Cadena 15 de la ciudad de Huancayo, departamento de Junín.

Como diseño muestral se tomaron 10 emisiones de cada noticiario de la televisión de señal abierta de Lima, 3 emisiones del noticiario de cable y 4 emisiones de los noticiarios de la ciudad de Huancayo.

\section{Ámbito de la noticia}

Los resultados del análisis realizado a los noticiarios emitidos de lunes a domingo en Lima Metropolitana, indican que estos transmiten una mayor proporción de noticias referentes al acontecer nacional, las cuales conforman el $77.7 \%$ de su contenido, dejando sólo un $22.3 \%$ a las noticias de ámbito internacional.

\section{Alcance de las notas nacionales}

Con respecto al alcance o trascendencia del contenido de las notas nacionales en los noticiarios de la capital, los resultados del análisis permiten afirmar que todos los noticiarios tienen un mayor índice de notas de alcance local metropolitano y en segundo lugar de alcance nacional, siendo menor la proporción de las notas que tratan sobre el quehacer local regional. Podemos detallar entonces que el $60.0 \%$ del total de las emisiones tiene notas de alcance local metropolitano, mientras que el $25.1 \%$ son de alcance nacional y sólo el $14.9 \%$ corresponden a alcance local regional.

\section{Formato de las noticias}

El formato de notas más utilizadas en los noticiarios de la capital es el informativo con desarrollo, seguido por el informativo breve mientras que el resto de formatos se utiliza en mucha menor proporción. El 74.2\% de los noticiarios está compuesto por noticias informativas con desarrollo, mientras que las noticias informativas breves alcanzan el $13.6 \%$, y las entrevistas el 8.5\%. El resto de los formatos como reportaje, indicadores económicos, transmisión en vivo, video clip y otros, no llega en conjunto al $4.0 \%$ de participación dentro de los noticiarios.

\section{Comentarios durante las noticias}

La iniciativa de emitir comentarios antes o después de las notas, varía significativamente según cada noticiario, sin embargo, los resultados del análisis permiten afirmar que el estilo predominante de los noticiarios de la capital consiste en que los narradores sólo den una breve introducción antes de lanzar las notas. El promedio de comentarios en los noticiarios observados en las 10 emisiones es de 2.1 . 


\section{Aéreas temáticas de las noticias}

Las áreas temáticas con mayor presencia dentro de los noticiarios fueron política y policiales, con promedios de $27.4 \%$ y $21.4 \%$ respectivamente, en el total de las emisiones observadas. Por debajo encontramos áreas como tragedias y accidentes con el 7.5\%, deportes con el $7.4 \%$, y TV y farándula con el $6.3 \%$. El resto de áreas temáticas entre las cuales se encuentran problemática del ciudadano, problemáticas sociales, derechos humanos, justicia, economía, salud, educación, medio ambiente, catástrofes naturales, religión y moral, ayuda social, arte y cultura, trabajo y otras, no llegan al $4.0 \%$.

El área temática de política estuvo liderando las menciones debido a la coyuntura electoral de las elecciones municipales y regionales del 5 de octubre, teniendo en consideración que las observaciones de los noticiarios se realizaron en los días previos al evento electoral. Así, dentro del rubro de política el tema más mencionado fue las elecciones municipales con $14.1 \%$, seguido por política general con $6.9 \%$, luego el Congreso con $4.0 \%$ y finalmente elecciones regionales con $2.3 \%$.

En cuanto a las notas policiales, el mayor número de estas trató específicamente sobre robos / asaltos / delincuentes, asesinatos, agresiones y violencia sexual, y seguridad ciudadana, temáticas que tienen promedios de $8.6 \%, 2.6 \%, 2.0 \%$ y $1.8 \%$ respectivamente. Las notas de tragedias / accidentes tienen un $3.6 \%$ en accidentes automovilísticos y $3.9 \%$ en otros accidentes.

El estudio también analizó cuánto tiempo de los noticiarios era dedicado a cada área temática, y encontró que política y policiales son las que cuentan con más espacio, teniendo el $26.5 \%$ y el $21.8 \%$ respectivamente del total del tiempo del noticiario. Otras áreas temáticas con un tiempo significativo son TV y farándula con $8.6 \%$ y tragedias / accidentes con $6.1 \%$. El resto de áreas temáticas tiene una exposición menor al 5\%, como es el caso de deportes con el $4.3 \%$, problemática del ciudadano también con el $4.3 \%$, justicia con $3.7 \%$, problemáticas sociales con el $2.9 \%$, mientras que las otras áreas registran valores mucho menores.

Además también encontró que dentro del espacio utilizado para tratar la temática política, la mayor parte del tiempo lo utilizaron para hablar de las elecciones municipales con $13.5 \%$ de tiempo de exposición dentro del noticiario, dejándole a política en general un $6.1 \%$, al Congreso un $4.8 \%$ y a las elecciones regionales un $2.1 \%$.

En cuanto a las notas policiales, la mayor cantidad de tiempo se lo dedican a las que tratan sobre robos / asaltos / delincuentes con $8.8 \%$, luego seguridad ciudadana con $2.4 \%$ y asesinatos con $2.3 \%$.

\section{Actores sociales en los noticiarios}

Según demuestran los resultados del estudio, los actores sociales que tuvieron mayor presencia en los noticiarios analizados fueron los ciudadanos en general, con $19.8 \%$ seguido por los políticos con $17.5 \%$, y luego los delincuentes con $10.0 \%$. A continuación tenemos a los deportistas y dirigentes deportivos, con $8.2 \%$. Cabe mencionar que la gran mayoría de los deportistas y dirigentes que aparecieron en estas notas eran futbolistas o autoridades relacionadas al fútbol, debido a que la mayoría de notas deportivas trataban sobre este deporte.

Los otros actores sociales de la noticia tienen una presencia debajo del 6\%. Entre ellos se encuentran los personajes de la farándula con $5.2 \%$, las autoridades del gobierno central con $5.1 \%$, entre otros.

En cuanto al sexo de los actores sociales, se encontró que los noticiarios tienen un mayor índice de actores sociales masculinos, siendo el $63.2 \%$. La presencia de notas donde hombres y mujeres tienen igual protagonismo alcanzan el $20.4 \%$ y las que tienen como actor principal a la mujer son el $16.3 \%$.

La mayoría de hombres que aparecen en la noticia son políticos, ciudadanos, deportistas / dirigentes deportivos, y delincuentes, las mujeres superan a los hombres en personajes de la farándula.

En cuanto a los grupos etarios de los actores sociales, los resultados del análisis indican que en los noticiarios hay una mayoritaria presencia de adultos, los cuales representan el $94.1 \%$ de los actores sociales, mientras que los niños y adultos mayores son una minoría que tienen solo el $3.7 \%$ y $2.2 \%$ de presencia respectivamente. 


\section{Grupos favorecidos y desfavorecidos}

Los resultados de la investigación señalan que son dos los principales grupos que resultan favorecidos con la noticia, los intelectuales con $81.8 \%$ y los personajes de TV espectáculos con $67.8 \%$. En cambio los principales grupos que aparecen como desfavorecidos son los adultos mayores con $85.0 \%$, y los parlamentarios con $83.6 \%$.

\section{Calidad periodistica de las noticias}

Sobre la relevancia de la noticia, cabe mencionar que todas las notas tienen algún tipo de relevancia, ya sea intrínseca o de tratamiento. Los resultados del estudio indican que en el $88.6 \%$ de los noticiarios tiene notas con relevancia intrínseca, mientras el $11.4 \%$ tiene notas con relevancia de tratamiento.

En cuanto al uso de fuentes todas las notas emitidas tuvieron al menos una fuente, y al contabilizar cuantas fuentes suelen utilizar en cada nota, se encontró que el $64.1 \%$ de los noticiarios suelen utilizar una fuente en las noticias que emiten, el $24.3 \%$ emplean 2 fuentes y el $7.7 \% 3$ fuentes.

Sobre el aporte informativo de las fuentes, la mayoría de los noticiarios emite todas sus notas con algún aporte informativo, siendo estas el 99.4\%. Las notas con fuentes inconsistentes solo alcanzan al $3.4 \%$ del total, sin embargo el $96.6 \%$ de las notas del total de los noticiarios si tuvo consistencia.

Por otro lado tenemos a las notas controversiales, las cuales no se presentaron en todos los noticiarios. Del total de las notas controversiales, el $39.2 \%$ no tuvo contraste y el $60.8 \%$ si tuvo contraste.

\section{Ética periodística de las noticias}

En el caso de faltas a la ética periodística, se tomó en cuenta los casos de apelación a la emocionalidad, fuentes no identificadas, fuentes mal identificadas, trato discriminatorio o descalificatorio, imágenes de archivo distorsionadoras, respeto por el anonimato de los niños, niñas y adolescentes e imágenes violentas o con contenido sólo para adultos y los resultados del análisis señalaron que el $48.3 \%$ de las emisiones de todos los noticiarios incurrió en este tipo de faltas.
La falta a la ética periodística más recurrente es el uso de personas naturales como informantes o fuentes de noticias con $33.3 \%$ de casos, luego la apelación a la emocionalidad que llega a un índice de $31.7 \%$ del total de las emisiones revisadas, a continuación tenemos a imágenes violentas o contenido para adultos con $26.7 \%$, luego a trato victimizante con $25.0 \%$.

Proporción entre el tiempo de duración de las noticias y el tiempo destinado a comerciales

En promedio, los noticiarios analizados le dedican el $20.0 \%$ de su horario a la publicidad, quedándoles el $80.0 \%$ de duración del noticiario propiamente dicho.

\section{AGENDA PENDIENTE PARA UNA COMUNICACIÓN PARA LA PAZ}

Resulta importante empoderar a la sociedad civil fomentando su participación activa en la formulación de denuncias por contenido inadecuado de un programa de radio o televisión que implique la vulneración del Código de Ética.

Lamentablemente, no se cuenta con información estadística que nos permita saber la cantidad de denuncias que se han formulado, sin embargo, la estadística de sanciones por vulneración del Código de Ética nos arroja 1 en el 2014 y 1 en el 2015.

Lo cual podría obedecer a la falta de campañas de información dirigidos a la sociedad civil sobre los procedimientos de denuncias por contenidos inadecuados de un programa de televisión o radio, resultando importante que el Consejo Consultivo de Radio y Televisión difunda enérgicamente que inclusive por medios electrónicos los televidentes u oyentes pueden quejarse por la vulneración del Código de Ética.

Por otro lado, es oportuno realizar cursos de formación sobre una lectura crítica de los medios de comunicación que permitan a los públicos ejercer de mejor manera esta facultad.

El aumento en la cantidad de denuncias que eventualmente pueda recibir el Consejo Consultivo de Radio y Televisión, permitirá a los editores y jefes de información replantear y proponer cambios en sus enfoques discursivos 
para responder a la demanda ciudadana de una comunicación para la paz. Ello involucra culturizar e informar responsablemente al público con el contenido de los programas televisivos o radiales, dando cumplimiento y sentido al articulo 14 in fine de nuestra Constitución Política que prescribe: "Los medios de comunicación social deben colaborar con el Estado en la educación y en la formación moral y cultural."

Además debemos de tener en consideración que las noticas que se emiten cumplen un rol muy importante para la construcción de la opinión pública, pues su contenido define el sentido de la misma. Actualmente, al revisar dicho contenido observamos que los medios de comunicación construyen la cuestión criminal mediante discursos vindicativos, estereotipos criminales, repetición de noticias violentas y entre otros, generándose con ello un interés morboso y desmesurado por la violencia, pánico social, y una apatía manifiesta por la paz.

La propagación repetida de sucesos criminales en los medios de comunicación puede desarrollar miedo y desconfianza en la sociedad, limitando nuestras libertades y relaciones sociales, lo cual favorece el individualismo y la indiferencia. Sin embargo, es posible cambiar este paradigma limitante que no nos permite constituirnos en una nación cohesionada y pacífica, a través de una comunicación social positiva que genere una cultura para la paz.

Necesitamos un periodismo que aborde de manera más equilibrada los acontecimientos sociales, con nuevas prácticas que reemplacen a los actuales parámetros de información y comunicación, con una profunda responsabilidad ética en el tratamiento de las mismas. En donde se de notoriedad a las posibles soluciones desde la no-violencia, es decir, la transformación de la violencia por vías pacíficas. De esta manera, el análisis superficial y descontextualizado que realizan algunos medios de comunicación, en línea con los objetivos de control social, se sustituye por explicar y mostrar los factores que originan los acontecimientos.

Por ello, se requiere de un cambio normativo importante que incentive la responsabilidad social de los medios de comunicación, que pongan límites razonables a las comunicaciones que vulneren la dignidad humana. El artículo $5^{\circ}$ del Código de Ética de la Sociedad de Radio y Televisión establece que: "la autorregulación consiste en vigilar la calidad de la información que se brinda a través de la comunicación comercial, además de preservar y acrecentar la credibilidad de la misma. De igual forma, es tarea de la autorregulación el mantener vigentes $\mathrm{y}$ actuales los valores, principios fundamentales y reglas de la actividad que, para los propósitos de este documento se limitan a aquellos que rigen la relación con el público espectador y consumidor: a) Veracidad; b) Respeto a la dignidad de la persona humana; y c) Responsabilidad social." Por otro lado, el artículo $13^{\circ}$ prescribe que los ciudadanos podrán formulas sus quejas ante el incumplimiento del mencionado Código de Ética.

Por dicha razones se propone que durante la emisión de las noticias se coloque un cintillo que informe sobre la posibilidad de formular denuncias si el espectador considera que el medio de comunicación está incumpliendo con sus deberes éticos, ello fortalecerá la participación ciudadana para denunciar los contenidos que vulneren la dignidad de las personas. Asimismo, en aras de tutelar la objetividad en las noticias difundidas, se debe de colocar también las cifras oficiales respecto al tema tratado en la noticia. Finalmente, se debe de indicar si la noticia es repetida.

\section{CONCLUSIONES}

- Los medios de comunicación, especialmente los noticieros, nos muestran una extensa y repetida cobertura de eventos violentos, como crímenes, reflejando un profundo interés por informar que vivimos en una sociedad en conflicto.

- Los niveles de violencia que transmiten los medios de comunicación y sus efectos son coherentes con las estrategias de control social de los grupos de poder al afectar a la organización colectiva de los ciudadanos y sus deseos de participar en los procesos de cambio social.

- La comunicación para la paz busca forjar un compromiso y un posicionamiento claro sobre los problemas estructurales que aquejan al Estado, y por ende a la sociedad. 
- El empleo de los estándares de la comunicación para la paz transforman significativamente los lineamientos para la elaboración y presentación de una noticia, pues en su preparación prevalece la calidad de su contenido, ya que existe por sobre todo la profunda preocupación por explicar de manera objetiva y ética las causas que ocasionan un hecho noticioso, y su posible solución.

- De acuerdo con las estadísticas analizadas podemos afirmar que los medios de radiodifusión no emplean satisfactoriamente los estándares de la comunicación para la paz en la elaboración y difusión de sus noticias.

- El análisis superficial y descontextualizado que realizan algunos medios de comunicación, en línea con los objetivos de control social, se sustituye por explicar y mostrar los factores que originan los acontecimientos.

- Necesitamos un periodismo que aborde de manera más equilibrada los acontecimientos sociales, con nuevas prácticas que reemplacen a los actuales parámetros de información y comunicación, con una profunda responsabilidad ética en el tratamiento de las mismas. En donde se de notoriedad a las posibles soluciones desde la no-violencia, es decir, la transformación de la violencia por vías pacíficas.

\section{FUENTES BIBLIOGRAFICAS}

ARÉVALO SALINAS, Alex Iván (2014). Periodismo y comunicación para la paz. Indicadores y marco regulatorio. En COMMONS - Revista de Comunicación y Ciudadanía Digital, 3, (1), 57-87.
ESPINAR, E. \& HERNÁNDEZ, M. (2012). El periodismo de paz como paradigma de comunicación para el cambio social: características, dimensiones y obstáculos. En Cuadernos de Comunicación e Información (CIC), 17, 209-237.

GASCÓN, M. C. (2008). Comunicando paz. Otros medios de comunicación desde el mismo laberinto. Madrid: Popular.

Organización de las Naciones Unidas. Resolución 53/243 de la Asamblea General de las Naciones Unidas, disponible en http://www. un.org/.

Congreso de la República. Constitución Política del Perú, disponible en http://www. congreso.gob.pe/.

Ministerio de Transportes y Comunicaciones. Texto Único Ordenado de la Ley de Telecomunicaciones, disponible en http://www. mtc.gob.pe/.

Congreso de la República. Ley de Radio y Televisión, disponible en http://www.mtc.gob. pe/.

Consejo Consultivo de Radio y Televisión. Estadísticas de la radio y televisión en el Perú - 2016, disponible en http://www.concortv.gob. pe/.

Lima Consulting. Estudio sobre consumo radial y televisivo - 2015, disponible en http:// www.concortv.gob.pe/ 